\title{
Tertiary Chorionic Villus
}

National Cancer Institute

\section{Source}

National Cancer Institute. Tertiary Chorionic Villus. NCI Thesaurus. Code C34310.

A stage in the development of the chorionic villi that occurs at approximately 21 days gestation, and which is characterized by the vascularization of the chorionic villi. 